\title{
Ferdinand de Saussure e a produção do objeto da Análise do Discurso
}

\author{
Claudiana Nair Pothin Narzettia
}

\begin{abstract}
Resumo
Os principais historiadores da Análise do Discurso francesa são unânimes em afirmar que a teoria do discurso assenta em alguns conceitos basilares de Ferdinand de Saussure. Os textos fundadores desse campo de investigação vão no mesmo sentido. Este trabalho visa a dar uma contribuição sobre o problema da relação entre a AD francesa e as formulações de Saussure, enfocando principalmente o modo como a leitura que Michel Pêcheux faz do célebre linguista possibilita a produção do objeto teórico discurso. Nosso ponto de vista consiste em considerar que uma importante chave de compreensão da relação da linguística de Saussure com a teoria do discurso pode ser encontrada quando se tem conhecimento do projeto teórico de Pêcheux e da prática teórico-epistemológica que preside a produção da Análise do discurso como campo de saber. Adotando uma perspectiva histórica, discutiremos questões ainda hoje marcadas por mal-entendidos e incompreensões, tais como: Qual o lugar dos conceitos de Saussure na teoria do discurso? Onde aparece concretamente o trabalho sobre o pensamento de Saussure na teoria do discurso? Por que Pêcheux tomou Saussure como base para a construção de uma teoria do discurso? Há continuidade ou descontinuidade (ruptura) entre a AD e Saussure? O conceito de discurso é a reformulação do conceito saussuriano de fala? O embasamento no pensamento de Saussure (e de outros linguistas) implica necessariamente uma inserção da AD como um ramo da linguística?
\end{abstract}

Palavras-chave: Análise do discurso francesa; Linguística; Ferdinand de Saussure. 


\section{Considerações iniciais}

O linguista suíço Ferdinand de Saussure (1857-1913), dado o alcance de suas teorizações, é considerado como aquele que lançou as bases não só para o desenvolvimento da linguística como ciência, mas também de outros campos de saber, tais como a Antropologia, a Semiologia e a Análise do discurso em sua orientação francesa.

Conforme Normand (2009, p. 117), no contexto do estruturalismo: "A palavra de ordem era a Ciência e os critérios de cientificidade. Saussure apareceu como aquele que introduziu, enfim, sua possibilidade na Linguística, até então muito pouco rigorosa e que não havia ainda encontrado seu 'verdadeiro objeto'".

Os principais historiadores da $\mathrm{AD}$ francesa são unânimes em afirmar que a teoria do discurso proposta por Michel Pêcheux e seu grupo assenta em alguns conceitos basilares do mestre suíço, tais como os de língua, fala e valor (Cf. MALDIDIER, 2003; COURTINE, 1999). Os textos fundadores desse campo de investigação, por sua vez, vão no mesmo sentido (Cf. PÊCHEUX, 1997; PÊCHEUX; FUCHS, 1997).

Trabalhos atuais, localizados tanto no campo de uma história da linguística (ou das ideias linguísticas) quanto no campo da própria $\mathrm{AD}$, têm-se ocupado de uma reflexão sobre o modo como a teoria do discurso ter-se-ia embasado nos conceitos formulados por Saussure, com intuito de identificar se há continuidades ou descontinuidades entre a $\mathrm{AD}$ francesa e o pensamento de Saussure (Cf. PUECH, 2005; POSSENTI, 2004). No entanto, o que se nota são reflexões esparsas, às vezes pontuais, que se, por um lado, preenchem algumas lacunas quanto a essa questão, por outro não a esclarecem completamente.

Nesse contexto, este trabalho visa a dar uma contribuição sobre o problema da relação entre a AD francesa e as formulações de Saussure, enfocando principalmente o modo como a leitura que Pêcheux faz do célebre linguista possibilita a produção do objeto teórico discurso. Nosso ponto de vista consiste em considerar que uma importante chave de compreensão da relação da linguística de Saussure com a teoria do discurso pode ser encontrada quando se tem conhecimento do projeto teórico de Pêcheux e da prática 
teórico-epistemológica que preside a produção da Análise do discurso como campo de saber.

O projeto teórico de Pêcheux era elaborar uma teoria do discurso e um método de análise do discurso sustentado por essa teoria. A Análise do discurso (enquanto unidade que engloba a teoria e o método) poderia constituir um instrumento para as ciências humanas e sociais, favorecendo a produção de conhecimentos científicos nesse campo.

As questões a serem abordadas aqui são: Qual o lugar dos conceitos de Saussure na teoria do discurso? Onde aparece concretamente o trabalho sobre o pensamento de Saussure na teoria do discurso? Por que Pêcheux tomou Saussure como base para a construção de uma teoria do discurso? Há continuidade ou descontinuidade (ruptura) entre a AD e Saussure? O conceito de discurso é a reformulação do conceito saussureano de fala? O embasamento no pensamento de Saussure (e de outros linguistas) implica necessariamente uma inserção da AD como um ramo da linguística? Pêcheux, com suas formulações, queria intervir no desenvolvimento da linguística como ciência?

\section{As bases epistemológicas de Pêcheux}

O trabalho teórico (ou prática teórico-epistemológica) de Michel Pêcheux ao produzir a Análise do discurso enquanto um campo de saber estava embasado no "Materialismo Dialético" (ou "Dialética Materialista"), tal como concebido por Althusser na primeira fase de seu pensamento. O Materialismo Dialético (MD), delineado por Althusser a partir de uma articulação entre o pensamento de Marx e o pensamento dos teóricos da epistemologia histórica francesa, tais como Gaston Bachelard, Georges Canguilhem e Alexandre Coyré, era concebido como uma teoria das práticas e da prática teórica em especial - uma teoria do conhecimento científico e de sua história.

Alguns postulados centrais do MD do grupo althusseriano podem ser encontrados em dois textos publicados por Pêcheux sob o pseudônimo de Thomas Herbert: "Reflexões sobre a situação teórica das ciências sociais e, especialmente, da psicologia social” (1966); "Observações para uma teoria geral das ideologias" (1968). 
O primeiro é que uma ciência não nasce no vazio, mas num campo habitado por ideologias teóricas (enquanto conjunto de representações falseadas, distorcidas e parciais da realidade), com as quais efetuaram uma ruptura. O que separa ideologia e ciência é um corte epistemológico que instaura uma descontinuidade qualitativa e histórica, uma vez que se inaugura uma nova problemática. A partir de então, o passado da ciência recém-nascida é revelado como ideologia.

O segundo postulado é que a ciência nova só se constitui sob a condição de produzir seu objeto. A condição para a produção de novos objetos, em ruptura com as meras representações ideológicas, é a existência de um "aparelho de transformação". Este consiste em dois elementos: conceitos científicos e instrumentos técnicos.

Herbert (1973) dá o exemplo da luneta. Originalmente instrumento técnico da navegação, foi transformado por Galileu em telescópio, por meio de uma teoria ótica. Imbuído de uma teoria científica, Galileu possibilitou ver novos objetos antes não vistos, os quais suscitaram uma redefinição dos objetos existentes e uma nova teorização que rompia com certas garantias empíricas (especialmente aquelas dadas pela visão) do "sistema teórico" anterior. O desenvolvimento dessa nova teoria, livre daquelas garantias ideológicas, tornou possível a produção de novos instrumentos científicos, que vieram substituir os instrumentos técnicos antes utilizados. Os instrumentos científicos são, assim, teorias materializadas - nos instrumentos científicos, estão embutidos os conceitos produzidos.

No caso das ciências humanas e sociais, os instrumentos, na maioria dos casos, são os próprios conceitos científicos. Nesse campo, portanto, a produção de novos objetos necessitava ir buscar nas ciências já constituídas os instrumentos (conceitos científicos) necessários. Segundo o que propunha o grupo althusseriano, apenas três ciências poderiam, de fato e de direito, receber esse status: o Materialismo Histórico, a Psicanálise e a Linguística. Portanto, elas (e apenas elas) poderiam fornecer os instrumentos teóricos necessários para a construção do objeto de outras ciências. E é nelas que Pêcheux vai buscar os conceitos-instrumentos para formulação, no primeiro momento, do objeto da teoria do discurso que ele objetivava produzir. 
${ }^{1}$ Vale ressaltar aqui que o objeto discurso formulado por Pêcheux é definido, a nosso ver, a partir de uma problemática sóciohistórica (marxista), que se sobrepõe à perspectiva linguística. Evidentemente, esse conceito é produzido também a partir de um trabalho sobre conceitos linguísticos, e a Linguística é essencial nesse processo. Assim, é somente devido aos objetivos deste trabalho, quais sejam, apontar o papel de Saussure na produção do discurso como objeto, que nos atemos ao papel de Saussure, sem expor o papel seminal do $\mathrm{MH}$, que no entanto seria necessário para sua melhor compreensão.
No entanto, o trabalho teórico é um trabalho de transformação, e não simplesmente de transposição de conceitos. Sendo assim, os conceitos formulados originalmente nas ciências que atuam como instrumentos científicos sofrem críticas, deslocamentos, torções, enfim, transformações, para responder a um conjunto de questões que não são mais as de seu campo original. Além disso, o trabalho teórico caracteriza-se como uma articulação de conceitos provenientes de teorias diversas e não como mera interdisciplinaridade. A transformação dos conceitos é condição para a articulação teórica.

\section{A problematização da dicotomia língua e fala e a produção do objeto discurso}

Conforme dissemos acima, a epistemologia que embasa o trabalho teórico de Pêcheux estabelece que a primeira condição para o surgimento de uma ciência é a produção de seu objeto. Esse objeto é produzido por um trabalho do pensamento (por uma prática teórica), e não se confunde com os objetos empíricos, cujo funcionamento particular e concreto a teoria deve explicar.

Assim, a produção do objeto da teoria do discurso por Pêcheux passou por um trabalho de transformação de conceitos provenientes das três ciências acima citadas. A linguística é, portanto, parte do aparelho de transformação necessário à produção do objeto teórico discurso, uma vez que é uma ciência constituída. ${ }^{1}$

Conforme Pêcheux, a origem da Linguística científica "pode ser marcada com o Curso de Linguística Geral" (PÊCHEUX, 1997, p.61). Ao buscar a ordem da língua, "Saussure pôs-se a pensar contra seu tempo, rompendo com uma série de interrogações pré-linguísticas sobre a linguagem e suas determinações biológicas, lógicas, sócio-históricas ou filosóficas" (PÊCHEUX, 1999, p. 9).

No que diz respeito à Linguística e, mais especificamente, ao pensamento de Saussure, os conceitos de lingua e fala, conforme definidos no Curso de Linguística Geral, são o ponto de partida para a produção do objeto teórico discurso.

Analisando a tese de Saussure segundo a qual a língua é social e exterior aos indivíduos, enquanto a fala é individual, Pêcheux argumenta que esses conceitos não dão conta de toda 
a produção de linguagem. Defende o autor que seria necessário propor um "nível intermediário" entre a língua e a fala, que seria o nível do discurso.

Parece indispensável colocar em questão a identidade estabelecida por Saussure entre o universal e o extra-individual, mostrando a possibilidade de definir um nível intermediário entre a singularidade individual e a universalidade, a saber, o nível da particularidade que define "contratos" linguísticos específicos de tal ou tal região do sistema, isto é, feixes de normas mais ou menos localmente definidos, e desigualmente aptos a disseminar-se uns sobre os outros. (PÊCHEUX, 1997, p. 73-74)

Qual seria a especificidade do nível do discurso? Em que se distingue da língua e da fala? O discurso não seria nem universal (válido para todos os falantes de dada comunidade linguística), como a língua, nem singular/individual (lugar da liberdade do falante), como a fala. O discurso constituiria o nível da particularidade, sendo determinado pelos interesses de determinadas classes sociais, na luta ideológica de classes. Ele se define como um subconjunto, situado em um nível irredutível tanto aos elementos individuais que a ele pertencem quanto ao conjunto mais amplo que o contém.

Pêcheux toma o exemplo de um discurso de um deputado na Câmara e argumenta que este pode ser analisado do ponto de vista da Linguística, como pertencendo à ordem da fala $\mathrm{e}$, por conseguinte, como espaço da manifestação da liberdade individual; ou, ainda, esse mesmo discurso pode ser analisado como pertencendo à ordem da língua, sendo regido por regras linguísticas que caberia descrever. No entanto, esse discurso pode ser analisado, do ponto de vista de Pêcheux, como:

[...] uma parte de um mecanismo em funcionamento, isto é, como pertencente a um sistema de normas nem puramente individuais nem globalmente universais, mas que derivam da estrutura de uma ideologia política, correspondendo, pois, a um certo lugar no interior de uma formação social dada. (PÊCHEUX, 1997, p. 76-7)

O discurso, como nível intermediário entre a língua e a fala e correspondendo a posições ideológicas de classe, não se confunde com nenhum dos conceitos da mais famosa dicotomia saussuriana. No entanto, o discurso mantém uma relação com a língua, tal como definida por Saussure (sistema 
de signos dotado de um funcionamento interno estruturado, regular; sistema de valores).

No que diz respeito à relação do discurso com a língua, peça chave da teoria do discurso é a tese de que a língua se apresenta como "a base comum de processos discursivos diferenciados", o que traz como consequência uma articulação do Materialismo Histórico com a Linguística. Pêcheux pensa a relação da língua com os discursos, em primeiro lugar, como uma oposição entre aquilo que é geral e reiterável (a língua) e aquilo que é múltiplo (processos discursivos diferenciados):

O sistema de língua é, de fato, o mesmo para o materialista e para o idealista, para o revolucionário e para o reacionário, para aquele que dispõe de um conhecimento dado e para aquele que não dispõe desse conhecimento. Entretanto não se pode concluir, a partir disso, que esses diversos personagens tenham o mesmo discurso. (PÊCHEUX, 1988, p. 91)

O sistema linguístico, constituído por um conjunto de estruturas fonológicas, morfológicas, sintáticas, é, para Pêcheux (1988, p. 91), "dotado de autonomia relativa que o submete a leis internas, as quais constituem, precisamente o objeto da Linguística". Pêcheux entende que cabe à Linguística estudar e descrever, conforme estabelecera Saussure, tais estruturas. Tal estudo, imanente, é possível porque o sistema linguístico possui uma autonomia relativa que permite tal estudo.

A autonomia relativa da língua, que Pêcheux menciona, diz respeito à luta de classes. Os discursos, inversamente, em vez de gozarem de autonomia, inscrevem-se no interior dessas lutas e essa é a razão da sua diferenciação. Pêcheux traduz essa oposição numa fórmula: a língua é indiferente à luta de classes, mas as classes não são indiferentes à língua em suas lutas:

A "indiferença" da língua em relação à luta de classes caracteriza a autonomia relativa do sistema linguístico e [...], dissimetricamente, o fato de que as classes não sejam "indiferentes" à língua se traduz pelo fato de que todo processo discursivo se inscreve numa relação ideológica de classes. (PÊCHEUX, 1988, p. 92)

Os discursos "usam", sem dúvida, a língua; mas o fato de eles, assim como a ideologia (da qual são uma forma de materialidade), se distribuírem em regiões; o fato de variarem segundo posições de classe e de se apresentarem sob formas teorizadas ou práticas, não vem das formas da língua. 
Evidentemente, analisando os discursos tal com eles se apresentam no seu modo de existência histórica e analisando neles seus efeitos de sentido, a AD pecheutiana depara-se constantemente com fenômenos que envolvem considerações sintáticas, mas, na perspectiva em que ela se coloca, esses fenômenos não são encarados como estritamente linguísticos. A sintaxe entra nas considerações apenas como uma condição formal de efeitos de sentido cuja causa material extravasa o dominio do linguístico. Para marcar bem a sua perspectiva, Pêcheux insiste em dizer que seus conceitos não são linguísticos. Vejamos o que ele diz na conclusão de Semântica e discurso:

Os termos: interdiscurso, intradiscurso, efeito de préconstruído e efeito-transverso - introduzidos ao longo deste trabalho e que justamente caracterizam, segundo o que pensamos, a forma da discursividade - não correspondem, portanto, a fenômenos linguísticos: representam, em relação à base linguística, a existência determinante do todo complexo das formações ideológicas, submetido, em condições históricas sempre específicas, à lei "geral" de desigualdade que afeta essas formações (enquanto ideologias práticas e ideologias teóricas, e através de suas características ao mesmo tempo "regionais" e de classe) no processo de reprodução/ transformação das relações de produção existentes. (PÊCHEUX, 1988, p. 259)

O ponto de vista a partir do qual Pêcheux produziu o objeto teórico "discurso" é radicalmente diferente daquele com que Saussure produziu o objeto teórico "língua". Por isso, Pêcheux insiste em dizer que o seu objeto "não é um objeto linguístico, mas um objeto sócio-histórico onde o linguístico intervém como pressuposto" (PÊCHEUX; FUCHS, 1997, p. 188).

Assim, a teoria do discurso formulada por Pêcheux supõe uma distinção entre língua e discurso, propondo a existência paralela de uma ordem da língua e uma ordem do discurso, cada uma com seus elementos constitutivos. Mas supõe também que o discurso mantém uma relação com a língua, acima exposta, o que significa que são objetos que se entrecruzam, mas nunca se confundem ou se subsumem. Um ponto importante a salientar desde já - o objeto língua é concebido na AD de Pêcheux tal como definido por Saussure no CLG; é o conceito saussuriano de língua que está pressuposto na teoria do discurso.

Por outro lado, o discurso não é a reformulação da fala. Não seria exato dizer que a crítica de Pêcheux à dicotomia 
saussuriana de língua e fala e a produção do objeto discurso teriam o objetivo de recuperar aquilo que, em seu processo de constituição científica, a Linguística teria "recalcado", ou seja, a fala. Pêcheux não objetivava redefinir o conceito de fala e transformá-lo em algo regular, passível de descrição, ou, ainda, devolver a esse conceito suas determinações sociológicas. Na verdade, o projeto de Pêcheux consistia na produção de um novo objeto teórico. Segundo Maldidier (2003, p. 22) o conceito de discurso é teorizado com apoio crítico em Saussure, mas é construído no seio do dispositivo elaborado por Pêcheux: a análise automática é "a oficina em que se apreende o objeto novo".

Conforme Pêcheux:

[...] a discursividade não é a fala (parole), isto é, uma maneira individual "concreta" de habitar a "abstração" da língua; não se trata de um uso, de uma utilização ou da realização de uma função. Muito pelo contrário, a expressão processo discursivo visa explicitamente a recolocar em seu lugar (idealista) a noção de fala (parole) [...]. (PÊCHEUX, 1988, p. 91)

Essa formulação do autor em sua obra mais madura, Semântica e discurso, encontra embasamento na análise epistemológica que Haroche, Henry e Pêcheux (2007) fazem da noção saussuriana de fala.

Os autores propõem que o pensamento de Saussure contém um núcleo científico, onde reside a ruptura epistemológica com o passado pré-científico da linguística, que convive com noções pré-científicas remanescentes desse mesmo passado. Esse núcleo consiste nos conceitos de língua e de valor (e no princípio da subordinação da significação ao valor). Já o resíduo contém noções como as de fala, ideia, instituição social, entre outras. Portanto, para Pêcheux, a fala não é um conceito científico que pode ser objeto de ciência; ele é "resíduo não-científico da análise" da teoria saussuriana (PÊCHEUX, 1997, p. 62).

A definição da fala como o aspecto individual da linguagem; lugar da liberdade do falante (seu "ato de vontade e inteligência"); e domínio em que os falantes criam as analogias responsáveis por modificar a língua no tempo, "autoriza a reaparição triunfal do sujeito falante como subjetividade em ato, unidade ativa de intenções que se realizam pelos meios colocados a sua disposição" e aparece como "um caminho da liberdade humana" (PÊCHEUX, 1997 [1969], p.71). 
Segundo Haroche, Henry e Pêcheux (2007), noções como as de liberdade do falante e de ideia, implicadas na definição da fala, são incompatíveis com a perspectiva antissubjetiva que determina a produção de conceitos de língua, sistema e valor, pelo mestre suíço, sendo portanto incompatíveis com esse núcleo científico: "a subordinação da significação ao valor [...] tem precisamente por efeito interromper bruscamente todo retorno ao sujeito quando se trata da língua" (HAROCHE; HENRY; PÊCHEUX, 2007, p. 17).

Saussure, ao acentuar o papel dos sujeitos falantes na criação de analogias, que ocorre no domínio da fala, mas posteriormente vem afetar a língua, estaria retomando "uma ideologia individualista e subjetivista da 'criação'," (HAROCHE; HENRY; PECHEUX, 2007, p. 20), segundo a qual a criação é puramente individual. Tratar-se-ia, assim, de uma orientação antropológica ou humanista, que toma o sujeito e suas intenções como ponto de partida para a explicação de fatos linguísticos. Essa solução seria pré-científica, porque apelaria ao sujeito como princípio explicativo, o que é abandonado nos conceitos de língua-sistema-valor.

Já em 1975, Pêcheux e Fuchs alertavam:

[...] diremos que em relação ao termo "discurso" [...] há dois equívocos complementares a serem evitados. $\mathrm{O}$ primeiro consiste em confundir discurso e fala (no sentido saussuriano): o discurso seria então a realização em atos verbais da liberdade subjetiva que "escapa ao sistema" (da língua). Contra esta interpretação reafirmamos que a teoria do discurso e os procedimentos que ela engaja não poderiam se identificar com uma "linguística da fala". (PECHEUX; FUCHS, 1997, p. 178)

A grande diferença entre a fala e o discurso é a perspectiva não subjetivista de Pêcheux, que aliás está presente nas formulações científicas de Saussure. Nessa perspectiva, o sujeito não é criador, fonte ou origem de sua fala (tal como pressuposto por Saussure), mas um suporte de representações que ele recebe do interdiscurso. O que está pressuposto no conceito de fala (liberdade do falante, criação, subjetividade, idealismo, etc.) é incompatível com a perspectiva assumida por Pêcheux. Portanto, o discurso não é uma reformulação de uma noção pré-teórica. Sua definição parte de pressupostos inversos. 
2 "[...] os fenômenos linguísticos de dimensão superior à $\mathrm{frase}$ pode $\mathrm{m}$, efetivamente, ser concebidos como funcionamento, mas com a condição de acrescentar que esse funcionamento não é integralmente linguístico, no sentido atual deste termo, e que não se pode defini-los senão em referência à estrutura da formação social em que se encontram."
Até aqui destacamos os pressupostos teóricos que embasam a noção de fala para demonstrar que estes são contraditórios com o conceito de discurso e que, portanto, já de princípio, este não pode ser considerado uma reformulação daquela. É também pertinente, para demonstrar o mesmo argumento, destacar que as definições de fala e de discurso são muito diversas.

A noção de fala é estritamente linguística. Atesta isso não somente a definição da fala como as combinações pelas quais o indivíduo falante realiza o código da língua e o mecanismo psicofísico que lhe permite exteriorizar essas combinações (SAUSSURE, 1996), mas também o fato de Saussure entrever a possibilidade da constituição de um "linguística da fala" (diferente da linguística da língua, certamente).

O discurso, por sua vez, não é um objeto estritamente linguístico, mas sócio-histórico e não linguístico, tal como a fala fora concebida. Já em seus primeiros textos Pêcheux enfatiza isso:

[...] les phénomènes linguistiques de dimension supérieure à la phrase peuvent effectivement êtres conçus comme fonctionnement, mais à la condition d'ajouter que ce fonctionnement n'est pas intégralement linguistique, au sens actuel de ce terme, et qu'on ne peut les définir qu'en référence à la structure de la formation sociale où ils ont lieu. (PÊCHEUX, 1967, p. 218. grifos nossos) $)^{2}$

Afirmar que o discurso é um objeto sócio-histórico é dizer que ele é uma das materialidades da ideologia, isto é, lugar onde se materializam as representações ideológicas, "concretizadas" em material linguístico. A aliança entre ideologia, história e língua no conceito de discurso o afasta de ser mera reformulação da noção de fala.

\section{Considerações finais}

A partir da exposição acima desenvolvida, gostaríamos de questionar dois mal-entendidos sobre a relação entre a AD e o pensamento de Saussure.

O primeiro mal-entendido consiste na afirmação de que Pêcheux queria intervir no desenvolvimento da linguística, no ponto em que ela não estava desenvolvida. O pressuposto é que o corte inaugural da Linguística como ciência fora operado 
por Saussure e agora Pêcheux vinha atuar na produção de um corte intracientífico para desenvolver essa ciência. Nesse caso, ele objetivaria reformular o conceito de fala, de modo que se pudessem enxergar ali as regularidades não vistas por Saussure e corrigir erros como a presença do subjetivismo na noção saussuriana.

Esse mal-entendido não se sustenta se consideramos tudo o que demonstramos anteriormente. $\mathrm{O}$ discurso não é a reformulação da fala. Aquela crítica ao conceito de fala não é a crítica de um teórico da linguagem, que, possuindo uma orientação sociológica, quer reformular tal conceito "acrescentando" a ele uma dimensão histórica e ideológica. $\mathrm{O}$ discurso e o sentido não são objetos linguísticos, mas sóciohistóricos, e a semântica discursiva supõe uma mudança de terreno em relação à linguística. Pêcheux não estava engajado em promover o desenvolvimento da linguística criando um novo ramo dentro de seu campo.

O segundo mal-entendido é a afirmação de que Pêcheux rejeita Saussure, rejeita a herança de Saussure, uma vez que critica alguns pontos de suas teorizações e busca reinserir aquilo que Saussure e o estruturalismo teriam excluído: o sujeito e a história.

Se, nos anos 70, há um movimento de questionamento do corte de Saussure, do fechamento da Linguística numa ciência imanente da língua, objeto que excluiria fatores extralinguísticos (o sujeito e a história), e tentativas de promover o retorno do "recalcado", não é nesse movimento que a reflexão de Pêcheux se inscreve. Pêcheux não tinha por objetivo reconfigurar a linguística, recolocá-la no eixo social, tal como, por exemplo, Jean-Baptistte Marcellesi, um dos primeiros analistas do discurso, para quem a Linguística estruturalista, completamente equivocada em seus fundamentos, deveria ceder lugar a uma nova Linguística, a social.

Pêcheux não rejeita a herança de Saussure. Ao contrário, Saussure é uma efetiva herança para a teoria do discurso. $\mathrm{O}$ conceito de língua é tido na teoria do discurso como a base para os processos discursivos diferenciados em que classes diferentes, falando a mesma língua, sustentam discursos diferentes e contraditórios. A existência da Linguística como ciência da língua é uma condição sine qua non para a existência da teoria e da análise do discurso. Para Pêcheux, na produção 
da teoria do discurso e da análise do discurso não importa tanto o que Saussure supostamente excluiu, mas o que ele produziu, principalmente o conceito de língua. A língua, enquanto sistema com uma ordem própria e com autonomia relativa em relação às classes sociais e à luta de classes era a base para elaboração de processos discursivos diferenciados, estes sim não autônomos em relação às classes e suas lutas.

Há uma crítica de Pêcheux a certas formulações de Saussure (ao lado das concordâncias e deferências). Porém a crítica é voltada à produção de um novo objeto teórico. É o que se passa com a análise crítica da dicotomia saussuriana de língua e fala, que já comentamos: trata-se de um ponto de partida para propor a existência de um nível intermediário entre esses dois, o nível da particularidade. Em outras palavras, um ponto de partida para pensar outros problemas e fazer deslocamentos.

Portanto, entre a Análise do discurso e o pensamento de Saussure não se pode dizer que há continuidade nem descontinuidade, mas, como destacou Pêcheux algumas vezes, uma "mudança de terreno". Afirmar que a $\mathrm{AD}$ está em continuidade com a linguística saussuriana é uma ilusão retrospectiva embasada na institucionalização acadêmica ocorrida nos anos 80 (ou, pior ainda, resultado de uma incompreensão do projeto de Pêcheux e da definição de discurso). Embora a AD tenha se institucionalizado na linguística, ela não nasceu aí enquanto seu lugar epistêmico, mas no interior de uma teoria regional das ideologias inscrita por sua vez na ciência da História: anunciando seu empreendimento, Pêcheux afirma que seu objetivo era "desenvolver as consequências de uma posição materialista - no elemento de uma teoria marxista-leninista da Ideologia e das ideologias - com respeito ao que chamamos 'processos discursivos'" (PECHEUX, 1988, p. 32).

Não quisemos reacender a questão: análise do discurso é linguística? Objetivamos retornar à história da $\mathrm{AD}$, especificamente à produção do discurso como objeto, para entender sua especificidade, para discutir questões relativas à herança saussuriana. Dizer que a AD nasceu na história, dizer que o discurso não é objeto linguístico é insistir na perspectiva histórica das análises de discursos concretos contra uma gramaticalização da AD. 


\section{REFERÊNCIAS}

COURTINE. O discurso inatingível: marxismo e linguística (1965-1985). Cadernos de Tradução. Porto Alegre, no. 6, abr-jun, 1999. p. 5-18.

HAROCHE, Claudine; HENRY, Paul; PÊCHEUX, Michel. [1971]. A Semântica e o corte saussuriano: língua, linguagem, discurso. In: BARONAS, R. L. (Org). Análise do Discurso: apontamentos para uma história da noção-conceito de formação discursiva. São Carlos: Pedro \& João Editores, 2007, p. 13-32.

HERBERT, Thomas. [1966]. Reflexões sobre a situação teórica das ciências sociais e, especialmente, da psicologia social. Tempo Brasileiro, epistemologia, Rio de Janeiro, 2, (30, 31), p. 3-36, 1973.

. [1968]. Observações para uma teoria geral das ideologias. Rua, n.1, Campinas, 1995. Tradução de Carolina M. R. Zuccolillo, Eni P. Orlandi e José H. Nunes. p. 63-89.

MALDIDIER, Denise. A inquietação do discurso: reler Michel Pêcheux hoje. Campinas: Pontes, 2003.

NORMAND, Claudine. Saussure. São Paulo: Estação Liberdade, 2009.

PÊCHEUX, M. Sobre a (des-)construção das teorias linguísticas. Lingua e instrumentos linguísticos, Campinas, n. 4/5, p.7-32, 1999.

Análise automática do discurso (AAD-69). In: GADET, Françoise; HAK, Tony (orgs.). Por uma análise automática do discurso: uma introdução à obra de Michel Pêcheux. 3. ed. Campinas: Editora da Unicamp, 1997. p. 61-161.

. Semântica e discurso: uma crítica à afirmação do óbvio. Campinas: Ed. da Unicamp, 1988.

Analyse de contenu et théorie du discours. Bulletin du C.E.R.P., 16, (3). p. 211-227, 1967. 
PÊCHEUX, Michel; FUCHS, Catherine. [1975]. A propósito da Análise Automática do Discurso: atualização e perspectivas. In: GADET, Françoise; HAK, Tony (orgs.). Por uma análise automática do discurso: uma introdução à obra de Michel Pêcheux. 2. ed. Campinas: Editora da Unicamp, 1997. p. 163-252.

POSSENTI, Sirio. Teoria do discurso: um caso de múltiplas rupturas. In: MUSSALIM, Fernanda; BENTES, Anna Christina (orgs.). Introdução à Linguística: fundamentos epistemológicos. São Paulo: Cortez, 2004. p. 353-392.

PUECH, Christian. Lémergence de la notion de " discours » en France et les destins du saussurisme. Langages, Paris, n. 159, p. 93-110, 2005. Disponível em: http://www.persee.fr/ web/revues/home/prescript/article/lgge_0458-726x_2005_ num_39_159_2654. Acesso em: 06-fev.2011.

SAUSSURE, Ferdinand de. Curso de linguística geral. 16. ed. São Paulo: Cultrix, 1996. 


\section{Abstract \\ Ferdinand de Saussure and the production of the Discourse Analysis object}

The main French Discourse Analysis historians are unanimous in declaring that discourse theory rests on some of Ferdinand de Saussure's fundamental concepts. The founding texts of this research field argue the same. This paper aims to provide a contribution towards the problematic relation between French Discourse Analysis and Saussure's formulations, focusing mainly on the way Michel Pêcheux's reading of the renowned linguist enables the production of discourse as a theoretical object. Our point of view considers that an important key to understand the relation between Saussure's linguistics and discourse theory could be found when one knows Pêcheux's theoretical project, and the epistemological and theoretical practice that guides the production of Discourse Analysis as a knowledge field. Adopting a historical perspective, we will discuss questions that still today are marked by misunderstanding and incomprehension, such as: Where does Saussure's concepts fit within discourse theory? Where in discourse theory does the work on Saussure's thinking emerge concretely? Why did Pêcheux take Saussure as a basis for building a discourse theory? Is there continuity or discontinuity (rupture) between Discourse Analysis and Saussure? Is the concept of discourse the reformulation of Saussure's concept of speech? Does having the work of Saussure (and other linguists) as basis necessarily mean that Discourse Analysis is a branch of Linguistics?

Keywords: French Discourse Analysis; Linguistics; Ferdinand de Saussure. 